\title{
Power Consumption Modeling of Base Station as per Traffic Generated
}

\author{
Madhu Sudan Dahal ${ }^{1}$, Jagan Nath Shrestha ${ }^{2}$, \& Shree Raj Shakya ${ }^{3}$ \\ ${ }^{1}$ PhD Research Scholar, Central Campus Pulchowk, Institute of Engineering, Nepal \\ E-mail:msndahal@gmail.com \\ ${ }^{2}$ Professor, PhD, Central Campus Pulchowk, Institute of Engineering \\ E-mail:jns@ioe.edu.np \\ ${ }^{3}$ Asst. Professor, PhD, Central Campus Pulchowk, Institute of Engineering \\ E-mail: shreerajshakya@ioe.edu.np
}

\begin{abstract}
Author Note
Madhu Sudan Dahal, Mechanical Department, Tribhuvan University

Your Name is now a PhD research scholar at the Tribhuvan University

This Paper highlights the development of power consumption model and addresses the energy efficiency improvement.

Correspondence concerning this paper should be addressed to Madhu Sudan Dahal, msndahal@gmail.com
\end{abstract}

\begin{abstract}
Base Station is the main contributor of energy consumption in cellular mobile communication. The traffic of base station varies over time and space. Therefore, it is important to quantify the influence of traffic generated on the power consumption. This paper investigates changes in the power consumption of base stations according to their respective traffic and develops a model for the power consumption as per traffic generated aiming to highlight the power consumption model development and address the power saving capabilities. The primary data in terms of power consumption and traffic load have been measured hourly on fully loaded 10 base stations for 10 days. The regression analysis shows the existence of a direct relationship between power consumption and traffic generated. A linear equation is developed is $Y=1.713 \times X+1.274$, where $Y$ is power consumption and $X$ is traffic generated, which shows that the power consumption of base stations linearly depends on the traffic generated. One noticeable point is that when the traffic is high, the developed linear equation indicates that the data fits well in the model but on the other hand, when the traffic is low, the developed linear equation explains less variability of the response around its mean. This paper also gives an overview of energy efficiency improvement possibility in base station.
\end{abstract}

Keywords : Base Station, Efficiency, Modeling, Power Consumption, Traffic

\section{Power consumption modeling of base station as per traffic generated}

Telecommunication is playing a significant role in the daily life of people in today's globalizing context. The tele density has surged to $100 \%$ this year in Nepal (Nepal Telecommunication Authority, 2015). Nepal had an annual GDP per capita of USD 696.9 in 2014 and every $10 \%$ increase in broadband penetration provides a $1.38 \%$ increase in GDP for low and middle-income countries (Broadband Commission, 2010). The growing interest in new and reliable services in mobile communications has resulted in an increased number of installed base stations worldwide. In addition, the traditional concept of base station deployment assumes continuous operation in order to guarantee the quality of service anywhere and anytime. Both of these reasons have synergistically contributed during the last decade to the significant growth of the total energy consumed by base stations of cellular network operators (Lorincz, Garma \& Petrovic, 2012). 
South American Journal of Academic Research

Special Edition May 2016

Nepal is severely facing energy crisis with an average 12 hours of load shedding per day so the challenge is to provide reliable and cost effective power solution. For this, a power consumption model is developed as per traffic generated. It is well known that the main source of energy consumption in cellular mobile networks is the base stations, with a share in total network consumption greater than 50 \% ( Deruyck, Vereeckeh, Joseph \& Martens,2010). The main cause for the green house emission in the world can be attributed to radio networks in mobile communications. It is however important to determine the consumption of the whole wireless access network and thus to model the power consumption of each part of this network. Within these networks, $10 \%$ of the energy is consumed by the user terminals, while $90 \%$ is caused by the base stations. These numbers indicated that the power consumption of wireless access networks is going to become an important issue in the coming years (Deruyk, Joseph \& Martens, 2011).

In a world of exploding, wireless communications, improving the power efficiency of radio networks is an important research topic (Fehske, Fettweis, Malodin \& Biczok, 2011). To evaluate the energy efficiency of today's mobile communication systems and to identify improvement areas for next generations system, a high level energy efficiency evaluation (E3F) has been developed within the Energy Aware Radio and neTworking technologies (EARTH) project (EARTH project, 2007-2013). This framework covers the complete system, including network and radios (Gunther et al ., 2011). It enables a quantitative evaluation in terms of efficiency under different traffic and load scenarios.

A power consumption model is developed based on the power consumption and the traffic generated by base stations. Energy efficiency at various loads viz, low traffic and high traffic are compared. The power consumption of base stations consists of two parts. The first part describes the static power consumption, a power figure that consumed already in an empty base stations and dynamic power consumption which changes with traffic load. Depending on the load situation, a dynamic power consumption part adds to the static. In this research, only dynamic power consumption with respect to traffic load has been considered. A power model is derived for typical base stations that is installed here in Kathmandu.

Only a few works have been done regarding the power consumption modelling of base stations. Reducing the energy consumption of base station, which is the main energy consumer, in the cellular networks has recently become an important research topic (Lorincz et al., 2012). The most remarkable contribution to this topic can be found where power consumption modeling of base stations has developed (Deruyk, Joseph \& Martens, 2011). But these contributions have not considered the real traffic load. To the knowledge of the authors, such study comprising of power consumption and traffic generated with real time data has not been yet carried out in Nepal.

\section{Methods}

A power consumption model as per traffic generation of a base station is proposed. An important parameter to investigate is the energy efficiency of the base station. The energy efficiency here is defined as the power consumption needed to cover a certain area (in $\mathrm{W} / \mathrm{m}^{2}$ ). The power consumption $\mathrm{PC}_{\text {area }}$ per covered area is then defined as (Deruyck, Joseph \& Martens, 2012):

$$
\text { PCarea }=\frac{\mathrm{P}_{e l}}{\pi R^{2}}
$$

with $\mathrm{P}_{\mathrm{el}}$ the power consumption of the base station and $\mathrm{R}$ the range of the base station. The lower the $\mathrm{PC}_{\text {area }}$, the more energy-efficient the base station is.

A base station is defined as the equipment needed to communicate with the mobile stations and with the backhaul network. The area covered by a base station is called as cell that is further divided into a number of sectors. Each sector is covered by a sector antenna, which is a directional antenna with a sector-shaped radiation pattern (Son, Kim, Hi \& Krishanmachari, 2011). 
To determine the load, measurements were done for an actual base station in the urban area of Kathmandu, Nepal. The power consumption of the 10 base stations for 10 days including weekend days were measured. The group of load-independent components i.e., the rectifier, the air conditioning and the microwave link were not included in these measurements. For the equipment considered, the voltage is constant (i.e. approximately $54 \mathrm{~V}$ ) and thus the current was measured. The power consumption $\mathrm{P}(\mathrm{t})$ at a certain time $\mathrm{t}$ is then determined as follows (in Watt):

$$
P(t)=V . I(t)
$$

with $\mathrm{V}$ the voltage (in Volt) and I the current at time $\mathrm{t}$ (in ampere).

The primary data of 10 base stations was collected for 10 days. The collected data includes current drawn and traffic load of respective base stations. The voltage of equipment is $54 \mathrm{~V}$ (constant) which is multiplied by current to get the power consumption. The average power consumption for each hour during the measurement period was determined, which gives the vector power. The normalized power consumption per hour was also obtained. Similarly, the traffic load of respective base stations was measured on hourly basis. Thus the total collected sample values for both power consumption and traffic load was $240(24 * 10)$ per site. The current was measured with an AC/DC current clamp. The value of the current was saved every second, which resulted in 8,64,000 samples for the measurement period of 10 days. For the week days, it was noticed that the power consumption at night is lower than during the day, because during the day more people are active than at night. For the weekend days, this difference in power consumption is smaller than for weekdays. The data collected for power consumption per hour for weekdays and for the weekend was also calculated. The measured equipment consumes between $1016 \mathrm{~W}$ and $1087 \mathrm{~W}$. Traffic is mostly high during the weekdays (Sunday to Thursday) and low during the weekend days (Friday and Saturday).

After collecting the primary data, regression analysis was done using Microsoft Excel. Regression analysis is a statistical tool for the investigation of relationships between variables. Here, power consumption and traffic load are the two variables. The casual effect of traffic load on power consumption of base station will be analyzed. The relationship between power consumption and traffic load will be identified.

\section{Results and discussion}

The relationship between the power consumption of base stations with respect to the traffic load is obtained. The data of power consumption of 10 different base stations and their respective traffic load were collected for 10 days on hourly basis. There were total 2400 sample values for both power consumption and traffic load.

It was found that the traffic load is high during morning and evening from 08:00 - 11:00 hrs and 18:00 - 20:00 hrs, which is shown in figure 1. The maximum traffic load is 143.6 erlang and minimum traffic is 3.3 erlang.

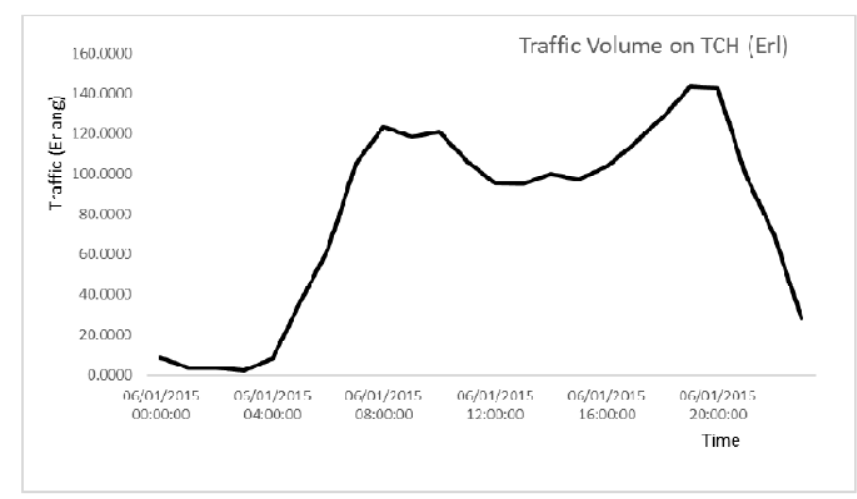

Figure 1: Traffic Pattern of base station 
South American Journal of Academic Research Special Edition May 2016

It was found that the power consumption of base station varies from $1.25 \mathrm{KWh}$ to 1.63 KWh. The range of power consumption did not vary so much as the traffic load varied largely which is shown in figure 2. The highest power consumption was recorded between 08:00 to 11:00 hrs for each day whereas the lowest power consumption was recorded from 00:00 to 6:00 hrs.

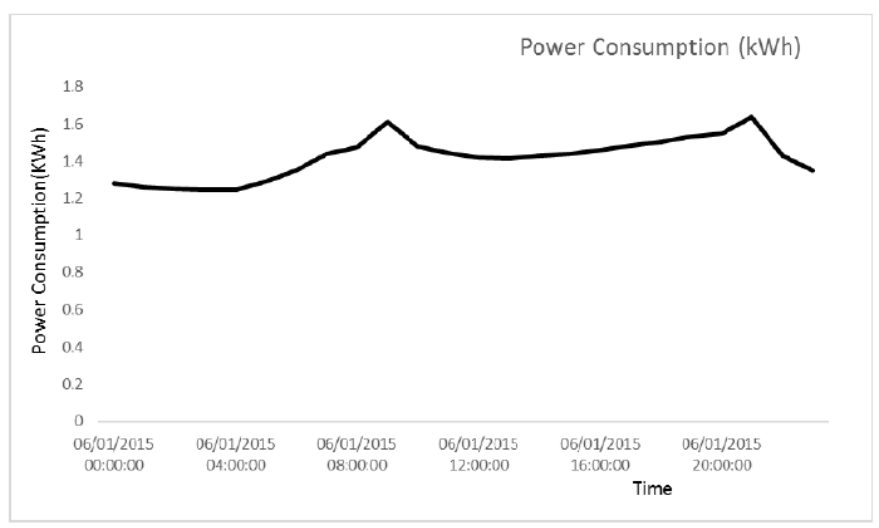

Figure 2: Power Consumption of Base Station

It was also found that the power consumption of each base station differed in weekdays and weekends. The traffic load of each base stations was seen high during 10:00 to 14:00 hrs. and lowest between 14:00 to 19:00 hrs.

The power consumption pattern is a direct consequence of a daily traffic pattern variation. It was observed that the increase in the traffic results in an increase in the power consumption of base station. A comparison between traffic load and power consumption is presented in figure 3. There is a direct correlation between the power consumption and respective traffic load. Figure 3 shows the comparison of power consumption and traffic load for 10 days, which clearly shows the correlation between power consumption and traffic load.

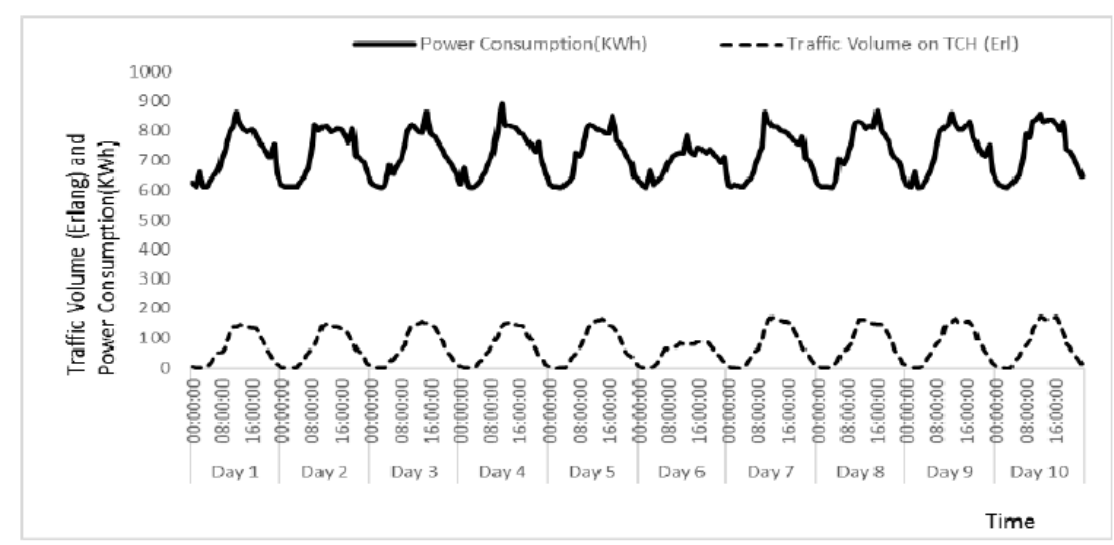

Figure 3: Power Consumption and Traffic load of Base Stations for 10 days.

The traffic load has maximum value of 230.137 Erlang and corresponding power consumption is $1.635 \mathrm{KWh}$ during 10:00 to 11:00 hrs. Figure 4 shows the power consumption and traffic load generation for a single day. When the traffic load is high, the correlation between power consumption and respective traffic load is also high. 


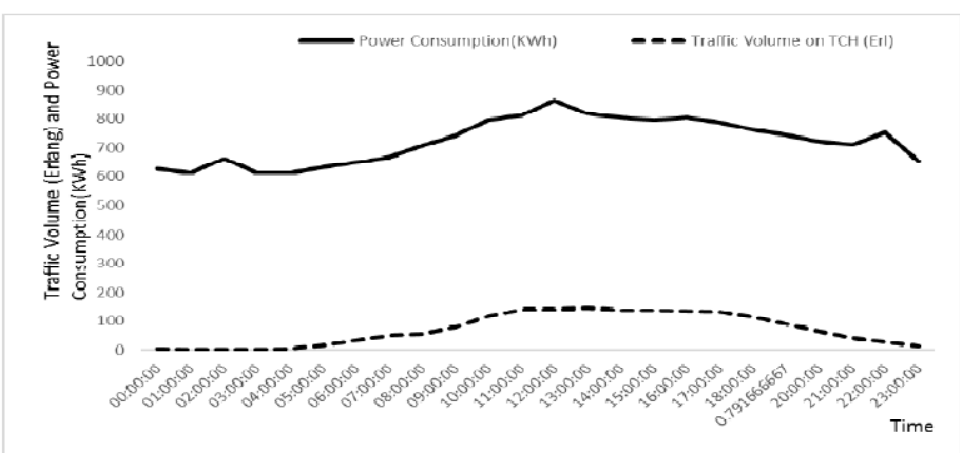

Figure 4: Traffic Volume and Power Consumption of a day of one Base Station.

To test the statistical model we have to check the value of $\mathrm{R}$ squared. The coefficient of determiniation, R Squared is the number that indicates how well data fit a statistical model. It is also known as the coefficient of determinaition. $0 \%$ indicates that the model explains none of the variability of the response around its mean. In this study, the value of $\mathrm{R}$ square varies from 0.765 to 0.949 which indicates that our model explains good variability of the response data around its mean. Adjusted R Squared lets the percentage of variation expalined only by the independent variables that actaully affect the dependent variable. Here Adjusted R square varied from .7648 to 0.9489 .

Table 1: R squared and Adjusted R squared value of different Base stations

\begin{tabular}{|c|c|c|}
\hline Base stations & R Squared & Adjusted R Squared \\
\hline Dhapasi & 0.7658 & 0.7648 \\
\hline Kalikasthan & 0.7870 & .7861 \\
\hline Maharajgunj & 0.8042 & 0.8034 \\
\hline New Baneshwor & .8142 & 0.8134 \\
\hline Panipokhari & 0.7931 & .7922 \\
\hline Sinamangal & 0.8167 & 0.8159 \\
\hline Sundhara & 0.8890 & 0.8885 \\
\hline TTC & 0.8000 & 0.7999 \\
\hline Jawalakhel & 0.8945 & 0.8940 \\
\hline Pulchowk & 0.9491 & 0.9489 \\
\hline
\end{tabular}

Based on the measured traffic load and the power consumption obtained for each base station, the goal is to develop a linear power consumption model as per traffic generated. The developed model must express power consumpiton of each base station as a function of currrent traffic load. In order to model the interdependence between the power consumption of each base station rack and corresponding traffic load, we used the following equation (Josip Lorincz, 2012)

$$
\mathrm{y}=\beta_{1} \mathrm{f}_{1(\mathrm{x})}+\ldots \ldots \ldots \beta_{\mathrm{p}} \mathrm{f}_{\mathrm{p}(\mathrm{x})}+
$$

According to Equation (1), response $y$ is modelled as a linear combination of function of independent variable $x$ and a random error . In this expression $f_{1(x)}(j=1, \ldots, p)$ are the terms for the model, while $\beta_{1}(j=1, \ldots, p)$ represents the coefficients. It is assumed that the model has upto $\mathrm{p}$ different terms and corresponding coefficients. Uncontrolled factors and experimental erros are modelled in above equation by and assumed to be uncorrelated and distributed with zero mean and constant variance.

In this linear model, terms are $\mathrm{f}_{1(\mathrm{x})}=1$ and $\mathrm{f}_{2(\mathrm{x})}=\mathrm{x}$. For $\mathrm{n}$ independent observations $(\mathrm{x} 1$, $\mathrm{y} 1), \ldots . .,(\mathrm{xn}, \mathrm{yn})$, the linear regression model becomes :

$$
\mathrm{y}=\mathrm{X} \beta+
$$


South American Journal of Academic Research Special Edition May 2016

Let the telecommunication traffic $\operatorname{Tr}[\operatorname{Erl}]$ be independent variable $\mathrm{x}$, while the meausred power $\mathrm{P}[\mathrm{W}]$ is response $\mathrm{y}$. Then the coefficients of the regression line are $: \beta_{1}[\mathrm{~W}]$ which represents the intercept and $\beta_{1}[\mathrm{~W} / \mathrm{Erl}]$ which represents the slope of line. Calculations were performed by means of a function regression which is a part of Excel. The obtained results are shown in the table 2.

Table 2: Slope and Intercept of different Base stations.

\begin{tabular}{|c|c|c|}
\hline Base stations & Intercept (a) & X Variable (b) \\
\hline Dhapasi & 636.1630 & 0.8547 \\
\hline Kalikasthan & 631.1256 & 0.7466 \\
\hline Maharajgunj & 629.1695 & 1.9822 \\
\hline New Baneshwor & 584.6320 & 1.0840 \\
\hline Panipokhari & 685.4675 & 0.8905 \\
\hline Sinamangal & 656.9946 & 5.10743 \\
\hline Sundhara & 697.3975 & 2.7711 \\
\hline TTC & 602.7391 & 1.3878 \\
\hline Jawalakhel & 626.3360 & 1.2840 \\
\hline Pulchowk & 621.7678 & 1.0227 \\
\hline Weighted Average & 637.1793 & 1.7131 \\
\hline Pure Weighted Average & 1.2743 & 1.7131 \\
\hline
\end{tabular}

The final developed equation of the above values is

$$
\mathrm{Y}=1.274+1.713 * \mathrm{x}
$$

where $\mathrm{Y}$ is the power consumption of base stations and $\mathrm{x}$ is the traffic generated .

The developed linear models have been plotted together with the measured results and linear regression lines having $95 \%$ confidence interval. The linear dependence of the power consumption on the traffic load was observed from above figures. An increase in the traffic load results in a linear increase of the base station power consumption.

When the traffic load is very low, the proposed linear models ensure some fixed amount of power consumption. Following table shows that the dependent variable is very small and can be neglected. The intercept value only ensures power cosnumption. So during no traffic also certain amount of power cosumption (intercept value) is used by base stations. The $\mathrm{R}$ squared value is minimum which ensures the result.

The linear equation at low traffic is $\mathrm{Y}=0.00057^{*} \mathrm{x}+1.22677$

Table 3: Equation and R square Value of sites

\begin{tabular}{|c|c|c|}
\hline Site & R Square & Equation \\
\hline Dhapasi & 0.3123 & $\mathrm{Y}=0.0004 * \mathrm{x}+1.2332$ \\
\hline Kalikasthan & 0.6174 & $\mathrm{Y}=0.0001{ }^{*} \mathrm{x}+1.2216$ \\
\hline Maharajgunj & 0.0158 & $\mathrm{Y}=0.0003 * \mathrm{x}+1.2478$ \\
\hline New Baneshwor & 0.0033 & $\mathrm{Y}=0.0012 * \mathrm{x}+1.1100$ \\
\hline Panipokhari & 0.8522 & $\mathrm{Y}=0.0003 * \mathrm{x}+1.3276$ \\
\hline Sinamangal & 0.5259 & $\mathrm{Y}=0.0015 * \mathrm{x}+1.200$ \\
\hline Sundhara & 0.4554 & $\mathrm{Y}=0.0002 * \mathrm{x}+1.3222$ \\
\hline TTC & 0.8594 & $\mathrm{Y}=0.0003 * \mathrm{x}+1.1917$ \\
\hline Jawalakhel & 0.0521 & $\mathrm{Y}=0.0012 * \mathrm{x}+1.1928$ \\
\hline Pulchowk & 0.7930 & $\mathrm{Y}=0.0002 * \mathrm{x}+1.2208$ \\
\hline
\end{tabular}

But when traffic load is low during off hours i.e. 2:00 am to 6:00 am, the correlation between power consumption and traffic load is low as shown in figure 5 . 


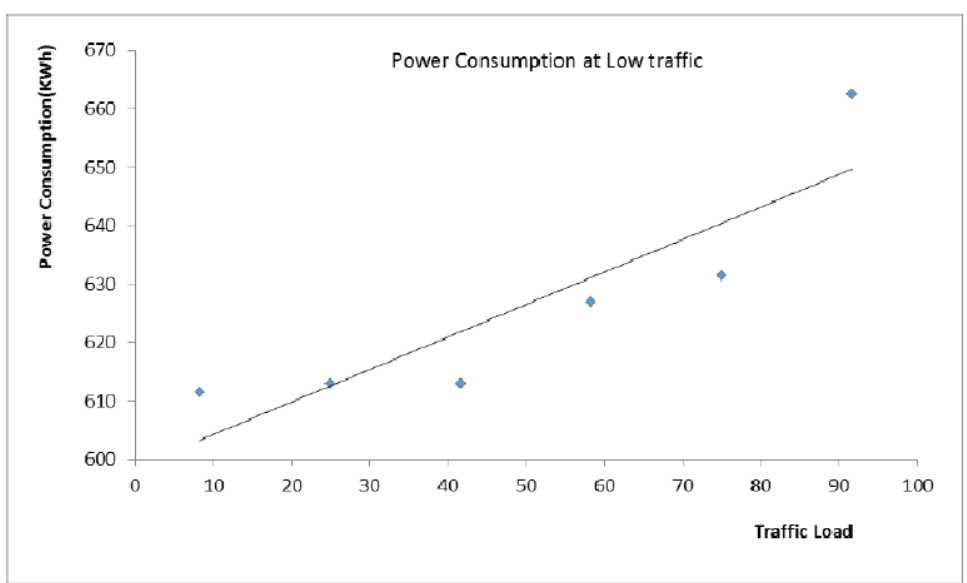

Figure 5: Normal Probability Plot at low traffic

Each linear model corresponds to the specific base station technology and base station of different technologies, manufacturers, production years of configurations might have different linear models (Lorincz et al., 2012).

\section{Conclusion and recommendations}

The main purpose of this research is to develop a model for the power consumption of base stations as per traffic generated. The impact of traffic on the power consumption of base stations is monitored. The traffic and power consumption data of 10 base stations were collected for 10 days for 24 hours on hourly basis with total sample values of 2400 . For each base station, the linear model has been developed. Each linear model has $\mathrm{R}$ squared value range from 0.765 to 0.949 and adjusted $\mathrm{R}$ squared value range from 0.764 to 0.948 , which validates the linear model. Similarly, the power consumption of base stations varies in accordance with the traffic load. This shows that there is a direct correlation between the base stations power consumption and the traffic load pattern. The proposed model with a significant percentage of confidence signifies the results obtained.

This implies that the linear power consumption model can be accepted as a model for precise expression of the interdependence between base stations power consumption and traffic load. During maximum traffic load, the developed linear model fits well but during minimum traffic, the linear model does not fit well as the $\mathrm{R}$ squared value ranges from 0.0033 to 0.3123 . At no traffic also, base stations still consume power which is given by intercept value. This intercept value will be nullified when the base station is in standby mode. Based on this research findings, further research on cell zooming considering the impact of traffic, spectrum, handover and quality of services has been recommended.

\section{References}

[1.] Albrecht fehske, G. F. (2011). The Global footprint of mobile communication: The ecological and economic perspective. Communications Magazine, IEEE, 49(8), 55-62.

[2.] (2010). Broadband Commission for Digital Platform. Retrieved from

www.broadbandcommission.org: www.broadbandcommission.org

[3.] (2007-2013). EARTH project . European community's seventh framework programme.

[4.] Gunther Aeur, V. G. (2011, October). How Much Energy is Needed to Run a Wireless network?

IEEE Wireless Communications Magazine, special issue on Technologies for Green Radio Communication Networks, 18.

[5.] Josip Lorincz, T. G. (March 2012). Measurements and Modelling of Base Station Power Consumption under Real Traffic Loads. Sensors.

[6.] Kyuho Son, H. K. (2011). Towards Energy - Efficient Operation of Base stations in Cellular Wireless Networks. Green Communciation. 
South American Journal of Academic Research Special Edition May 2016

[7.] M. Deruyck, E. T. (2011, March). Modelling and optimization of pwoer consumption in wireless access networks. Elsevier Computer Communication. doi:10:1016

[8.] Margot Deruyck, W. J. (2011). Power Consumption Model for Macrocell and Microcell Base stations. EUROPEAN TRANSACTIONS ON TELECOMMUNICATIONS, 1-14.

[9.] Margot deruyck, W. J. (2012). Power Consumption model for macrocell and microcell base stations. Emerging Telecommunications Technologies.

[10.] Margot Deruyck, W. V. (2010). Power Consumption in Wireless Access Networks. In Proceedings of European Wireless Conference, 924-931.

[11.] Margot Deruyk, E. T. (2011). Modelling the Energy Efficiency of Microcell Base stations. The First International Conference on Smart Grids, Green Communication and IT Energy-aware Technologies.

[12.] Nepal Telecommunication Authority. (2015). MIS Report. Kathmandu: NTA. Retrieved from http://nta.gov.np/en/mis-reports-en

[13.] Oh, E., Krishnamachari, B., Liu, X., \& Niu, Z. (2011). Toward dynamic energy efficient operation of Cellular network infrastructure. IEEE, 49, 56-61.

[14.] Oliver Arnold, F. T. (2010). Power consumption Modeling of Different Base Station Types in Heterogenous Cellular Networks. Future Network and Mobile Summit 2010 Conference.

[15.] Z., N., Wu.Y.j Gong, J., \& Yang, Z. (2010). Cell zooming for a cost- efficient green celluar networks. IEEE Communciation, 48, 74-79. 